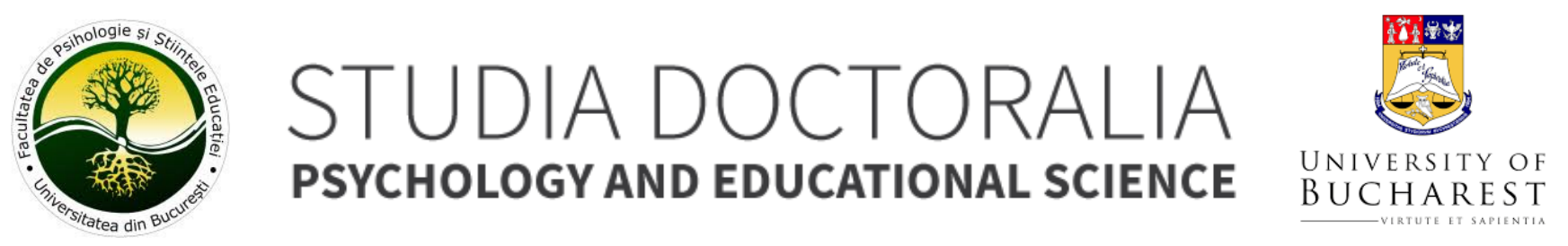

\title{
Burnout, empathy and well-being in medical and psychology students
}

\author{
Adrian Chiracu
}

Andreea Dona Iordan Dumitru

University Titu Maiorescu, Faculty of Dentistry

\section{ARTICLE INFO}

Article history:

Received 04-April-2021

Accepted 28-April-2021

Available online 01-May-2021

This article should be cited as: Chiracu, A., Iordan Dumitru, A. D. (2021). Burnout, empathy and well-being in medical and psychology students. Studia Doctoralia. Psychology and Educational Science, 12(1), 70-82 https://doi.org/10.47040/sd0000089

This is an open access article under the CC BY license (http://creativecommons.org/licenses/by/4.0/).

Corresponding author at: University of Bucharest, Department of Psychology, 90 Panduri Av, Bucharest, RO. Tel.: +40 (0) 31-425.34.45.

E-mail address: adrian_chiracu@yahoo.com

\section{ABSTRACT}

The present study aims to analyze the relationships between burnout, empathy and the well-being of medical and psychology students, as well as the differences in these variables depending on their specialization. The study was attended by 270 students, 94 males (35\%) and 176 females (65\%), aged between 18 and 48 years, $M=20.84, S D=$ 3.26. Regarding the specialization, 83 are enrolled at the Faculty of Dentistry Titu Maiorescu (31\%), 73 are enrolled at the Faculty of General Medicine and Pharmacy Carol Davila (27\%), and 114 are enrolled at the Faculty of Psychology and Educational Sciences, University of Bucharest (42\%). Burnout was measured with the Academic Burnout Scale (Zhang, Shi, Yun, Li, Wang, He, \& Miao, 2015), empathy was measured with the Jefferson Scale of Empathy, JSE (Hojat, Maxwell, Carroll, \& Cass, 2016), and well-being was measured with The Satisfaction with Life Scale, SWLS (Diener, Emmons, Larsen, \& Griffin, 1985). The results showed that medical students have higher levels of burnout than psychology students and lower levels of empathy and well-being. Empathy also moderates the relationship between burnout and wellbeing. These results can be used to develop intervention programs to reduce burnout and increase students' empathy in order to increase well-being.

Keywords: burnout, empathy, well-being, medical and psychology students

\section{INTRODUCTION}

\section{Empathy}

Empathy is an essential human component that facilitates successful social interactions (Ford, 1982) and encompasses, in a broad sense, an individual's reactions to the observation of another's experiences and is considered a combination of cognitive summation of a person's role and activation of emotional substitution in another person's condition (Davis, 1983). Empathy plays a central role in the 
formation and development of prosocial behaviors and moral reasoning.

The way in which this concept is delimited is not fully understood, although in the literature there are numerous studies designed to explore empathy. Thus, several perspectives have arisen and topics are brought up to clarify the subcomponents of empathy, how to measure them or the possible causes of individual differences (Melchers, Li, Haas, Reuter, Bischoff, \& Montag, 2016).

Empathy is a "hypothesis" we make about another person and the ability to transpose ourselves in other person, remaining objective. From a neuronal point of view, "mirror neurons" are responsible for the fact that we are prone to copy actions when we see them in other people. From the perspective of neural analysis, empathy acts on stimuli in the insula area of the brain, an area that facilitates the transfer of information between the frontal and emotional areas. It seems that empathy has deep roots both in our body and in evolutionary history. Studies have even revealed evidence that empathy has a genetic basis, and individuals have the ability to improve or inhibit their natural empathic ability (Ekman \& Friesen, 2003).

In simple terms, empathy can be defined as the ability to look from another person's perspective in order to assist that person in reducing stress (Batson, 1991), being different from sympathy or personal stress. Empathy has been associated with compassion, concern for others, selftranscendence, and altruism (Mikulincer, Shaver, Gillath, \& Nitzberg, 2005).

Starting from the hypothesis that there is a positive correlation between empathic understanding by the doctor, as an expression of sensitivity to patients and the creation of a secure environment between patient and doctor, as a basis for the development of therapeutic alliance, Siegel (2012) argues that the relationship between these concepts (which is likely to develop continuously) can be a continuous process during treatment sessions, a process supported by brain neuroplasticity. The author demonstrates through his study that there are neurobiological interrelations that take into account empathy. Thus, the common neurobiological areas between empathy and attachment may be "mirror neurons" as well as the central prefrontal area (Siegel, 2012).

Mirror neurons are indirectly related to the relationship between empathy and attachment. In addition, common areas of the brain correlated with the relationship between attachment and therapeutic relationship are the ventrolateral prefrontal cortex (Siegel, 2012), including the prefrontal cortex. In conclusion, empathy is an essential condition of a good doctor-patient relationship.

Over time, empathy has become a topic of interest to many neuroscientists and experts who have tried to explain how empathy can be used in the physician-patient relationship or in everyday life, but also how empathy can be cultivated or, on the contrary, stopped so that there are benefits both individually and within society. Being such a broad topic, many theories have been developed about the nature and components of empathy, but most have a common idea: empathy contains both emotional and cognitive elements (Baron-Cohen \& Wheelwright, 2004). The affective component presupposes an adequate emotional response to the mental state of another individual. On the other hand, the cognitive component is subject to the concepts of mind theory, that is, the ability to attribute mental states to others, an understanding that other people have feelings and thoughts different from ours (Baron-Cohen, 2001). Baron-Cohen and Wheelwright (2004) argue that these two components of empathy occur simultaneously and cannot be easily separated.

Empathy helps to understand the significance of others' behaviors, their feelings, connecting to others, and providing the right responses (Wheelwright \& Baron-Cohen, 2011). The role of empathy in the therapeutic process has been frequently mentioned, and it is argued that a continuous effort to form an empathic relationship with the patient, together with an unconditionally positive consideration for him, are necessary conditions for change to occur during the treatment sessions.

Most studies that considered the relationships between personality, attachment and empathy were addressed to doctors, nurses or social workers, the number of those who investigated these traits among medical students, future doctors, being relatively small and with research samples. limited.

Empathy is a relevant attribute for interpersonal relationships and refers to understanding and sensitivity to the mental states of others. The term empathy is used to designate two abilities: cognitive empathy - the mental taking over of the other's perspective and affective empathy - the vicarious sharing of the emotions of others (Whiten, 1991).

Regarding the evolution of empathy, there are two main arguments:

1. The demands of the increasingly complex social environment have led to the development of cognitive empathy because it facilitates relationships (Jolly, 1991). It allows people to understand and make predictions about the behaviors of others by assigning specific mental states. Cognitive empathy facilitates communication and social expertise, leads to the manipulation of others to achieve personal goals, facilitates the understanding of the emotions of others.

2. Affective empathy motivates people to manifest altruistic behaviors towards those around them (Vine, 1992). It facilitates emotion discrimination, promotes the acceptance of people's diversity. Affective empathy provides the fundamental basis for parent-child relationships and facilitates group cohesion. 
Empathy has been documented as an attribute of personality that involves the ability to respond to other people emotionally and cognitively without losing objectivity or identity. Empathy is associated with self-help behavior and is highly valued in professions oriented towards the good of the human being (Williams, 1989). Empathy is considered an essential component of a physician's overall competence (Hojat, Louis, Markham, Wender, Rabinowitz, \& Gonnella, 2011). Moreover, Del Canale, Louis, Maio, Wang, Rossi, Hojat and Gonnella (2012) explained the empathic involvement in patient care as a fundamental element of the doctor-patient relationship. They state that empathy is essentially a predominant cognitive attribute, not an affective or emotional one, that involves understanding, not feeling, the patient's experiences, concerns, and perspectives, combined with an ability to communicate that understanding and intent to help.

It is necessary to distinguish between empathy and sympathy. The interchangeable use of the two terms may not be problematic in social psychology, but it is important to separate them in the context of the medical professions that involve patient care. In social psychology, both sympathy and empathy can lead to similar outcomes, such as prosocial behavior, despite different behavioral motivations. For example, a prosocial behavior that is induced by empathic understanding is very likely to be triggered by altruistic motivation. A prosocial behavior induced by feelings of sympathy, however, is more likely to be activated by selfish motivations in order to reduce personal distress or to produce pleasant sensations (Hojat, 2016).

Unlike empathy, sympathy is a predominantly affective attribute that involves intense emotions about the patient's pain and suffering. By contrast, empathy is a predominantly cognitive entity. In the context of the medical professions, these two attributes lead to different behaviors and different outcomes towards patients. An empathetic physician will be more concerned with understanding the type and quality of the patient's experiences, while a sympathetic physician will be more concerned with feeling the degree, intensity, and quantity of the patient's experiences.

Due to its cognitive nature, excessive empathy is almost always beneficial in the doctor-patient relationship. On the other hand, due to its affective nature, excessive sympathy can be harmful in such a relationship and can prevent the neutrality that is so necessary in clinical decision-making, which can affect professional performance. Cognitively defined empathy always leads to personal growth, career satisfaction, successful professional and academic results, while emotionally defined sympathy can lead to burnout, exhaustion, vicarious trauma and compassionate fatigue (Hojat, 2016).

It can be assumed that the relationships between cognitive empathy and positive clinical outcomes are linear, meaning that outcomes become progressively better as empathy increases. By contrast, it is speculated that the relationship between sympathy and clinical outcomes is inversely proportional, meaning that sympathy may be beneficial up to a point, but beyond that point it may become useless.

Another important aspect of the differences between empathy and sympathy in the medical professions is that affectivity and emotion, the basic ingredients of sympathy, are too prone to change, while cognition and understanding, the basic ingredients of empathy, can be substantially improved. through education (Hojat, 2016).

Countless studies have shown a decrease in the level of empathy in medical students during medical training, and at the same time an increase in the level of empathy in students in psychology. For this reason, we aim to test the differences in empathy between medical students and psychology students, formulating the following hypothesis:

H1. Medical students have lower levels of empathy than psychology students.

\section{Burnout}

Burnout syndrome occurs as a result of long-term exposure to high levels of stress, being a social phenomenon characterized by exhaustion, both physical and mental (Vlachou, Damigos, Lyrakos, Chanopoulos, Kosmidis, \& Karavis, 2016). A person experiencing burnout feels frustrated due to the inability to perform their daily duties. This level of exhaustion is a challenge that can be encountered in all types of occupations and professions, especially in the field of care and the provision of medical services. The definition of the concept was given by Maslach (1982), the author calling the phenomenon as the loss of interest for colleagues to which is added the physical and emotional exhaustion, where the affected person no longer has positive emotions or respect for his clients or patients (Vlachou et al., 2016).

At first, the scientific community called the concept of "burnout" as pseudoscience and it was categorized as "pop psychology", but this changed when the MBI (Maslach Burnout Inventory) was published and empirical studies began to appear (Schaufeli \& Maslach, 1993). According to the model developed by Maslach and Jackson (1986), burnout comprises three dimensions: emotional exhaustion, depersonalization, and reduction of personal success (Vlachou et al., 2016).

Exhaustion. Although exhaustion reflects the stressrelated dimension of burnout, it fails to capture the critical aspects of the relationship that people have with their efforts. Exhaustion is not simply a lived state, it causes the individual's actions to distance themselves emotionally and cognitively from the goal of his work, possibly to cope with the stressors he faces (Maslach, Schaufeli, \& Leiter, 2001). Emotional exhaustion is a chronic state of exhaustion that 
occurs with excessive tasks and continuous discomfort during the activity (Shirom, 1989).

Depersonalization. It consists in acquiring a set of insensitive and cruel attitudes that the person manifests towards a client, patient or colleague (Shirom, 1989). It can be considered as a distance between oneself and the recipients of the services by actively ignoring the qualities that make them unique and involved. The requests they receive from clients / patients are easier to manage when they treat them only as objectives to be met. This situation is generally found in the field of medical, psychological or social services.

Decreased personal success. According to Byrne (1994), the relationship between inefficiency and the other two dimensions of burnout is a complex one. Often, the reduction of personal success appears as a fusion between exhaustion and cynicism. A job with exaggerated and overwhelming requirements contributes to the effects of depersonalization and exhaustion, which is likely to lead to a decrease in a person's sense of effectiveness (Maslach, Schaufeli, \& Leiter, 2001).

Over time this depletion syndrome has been categorized as a major professional hazard for a number of professions that use human interaction (human resources, teachers, medical staff, etc.). Interactions between service providers and beneficiaries requires personal and emotional contact that, manifested over a long period of time, can affect health, although the activity performed is engaging and satisfying in most cases (Maslach \& Leiter, 2016). Many studies that have addressed the issue of exhaustion have concluded that burnot is predominant among health professionals (Ahola \& Hakanen, 2007; Michels, Probst, Godenick, \& Palesch, 2003). Globally, high levels of burnout have been detected, although these may vary depending on the country, medical specialization, gender, professional degree (Kumar, 2016; Lee, Medford, \& Halim, 2015).

Physicians are repeatedly exposed to stress throughout their careers and are particularly susceptible to experiencing burnout. Its implications for doctors and the health system are vast. Those who experience it have a higher risk of making hasty decisions, having a hostile attitude towards patients, making more medical mistakes and having difficult relationships with co-workers. Other risks to which doctors are exposed can be: depression, anxiety, sleep disorders, fatigue, drug and alcohol use, marital dysfunction, premature retirement and in some cases even suicide.

A study conducted in the United States found that more than half of doctors have significant symptoms of burnout, a rate twice as high as other specialists in other fields. On top of that, it has been shown that the problem occurs prematurely, even during studies. Medical students and residents score higher on burnout and depression than those of their age who pursue careers in non-medical fields. And this phenomenon is not limited to doctors, nurses are also prone to high levels of burnout (Dyrbye, Shanafelt, Sinsky, Cipriano, Bhatt, Ommaya et al., 2017).

Regarding burnout among medical students, numerous studies have been conducted that have shown that they have a higher risk of exhaustion caused by increased academic load, massive demands, complex academic tasks, laboratory work. and last but not least, contact with patients suffering from certain diseases. A study conducted by Mayo Clinic showed that $53 \%$ of medical students have symptoms of burnout (Dyrbye et al., 2017).

Taking into account the above, we aim to verify whether medical students have higher levels of burnout than psychology students and establish the second hypothesis of this study:

H2. Medical students have higher levels of burnout than psychology students.

\section{Well-being}

Psychological well-being is defined as a set of characteristics responsible for positive human functioning and includes various dimensions related to resilience (Keyes, Shmotkin, \& Ryff, 2002).

According to Ryff and Singer (1998) the most important dimensions of psychological well-being are: autonomy, environmental control, personal development, positive relationships with others, purpose in life and selfacceptance.

Autonomy. In the literature there has been a considerable emphasis on qualities such as selfdetermination, independence and internal regulation of behavior. People with the ability to self-actualization show characteristics of autonomous functioning and resistance to enculturation. The perfectly functional person is described as having a place of internal control for self-assessment, a person who does not seek approval from others and evaluates himself based on his own standards. Individualization is seen as the salvation from the conventional, the person no longer relates to collective norms, beliefs, fears and the laws of the masses (Ryff \& Singer, 1996).

Environmental control. The ability of the individual to choose or create environments appropriate to his mental conditions is defined as a characteristic of mental health. Maturity is considered to require participation in a significant sphere of activity outside the self. Lifelong development is necessary in building the ability to manipulate and control complex environments, to advance in the world, and to change creatively through physical or mental activities (Ryff \& Singer, 1996).

Personal development. For the optimal psychological functioning it is necessary not only the finite acquisition of some characteristics, up to a certain moment, but also the continuation of the development of the personal potential, through personal growth and development. The individual's 
need to update and realize his potential is essential. Openness to experience, for example, is a key feature of a fully functioning person. Such an individual develops continuously, instead of obtaining a fixed state in which all problems are solved (Ryff \& Singer, 1996).

Positive relationships with others. Many theories emphasize the importance of warm and trusting interpersonal relationships. The ability to love is seen as a central component of mental health. People who succeed in building positive relationships with others are defined as having strong feelings of empathy and affection for all human beings and being more able to love, maintain deeper friendships, and identify more fully with others. The warm relationship with others is presented as a criterion of maturity. Theories in the field of adult development also emphasize the achievement of close unions with others (intimacy), as well as the guidance and guidance of others. Thus, the importance of positive relationships with others is repeatedly emphasized in theoretical models related to psychological well-being (Ryff \& Singer, 1996).

The purpose in life. Mental health is also defined by the inclusion of beliefs that give the feeling that there is a purpose and meaning in life. The definition of maturity also emphasizes a clear understanding of the purpose of life, a sense of direction and intentionality. Developmental theories refer to a variety of goals, constantly changing throughout life, such as being productive and creative (Ryff and Singer, 1996).

Self-acceptance. The most common criterion for assessing well-being highlighted in theoretical models is the self-acceptance of the individual. It is defined as a central feature of mental health, as well as a feature of selfactualization, optimal functioning and maturity. Possession of positive self-attitudes appears as a central feature of positive psychological functioning (Ryff \& Singer, 1996).

The six dimensions represent what it means to psychologically flourish and reach a person's true potential (Ryan \& So, 2001). Each of these dimensions articulates different challenges that arise as individuals strive for psychological well-being and are essential for the growth and psychological development of the individual (Keyes, Shmotkin, \& Ryff, 2002).

Ryan and So (2001) reconsidered the definition of wellbeing. They divided the concept into two components: the hedonistic - hedonic well-being (hedonic well-being), which deals with happiness and the eudaimonic - eudaimonic wellbeing (eudaimonic well-being), which deals with reaching human potential. The two approaches, hedonic and eudaimonic, are based on distinct conceptions of human nature and what constitutes a good society. Consequently, they are interested in how developmental and social processes are associated with well-being and implicitly and explicitly prescribe different approaches to life (Ryan \& So, 2001).
In general, in the field of health services, psychological studies have focused exclusively on the pathological side of things, studied the trials, the difficulties faced by medical staff, burnout and maladaptive methods of coping, leaving aside everything related by the healthy and positive approach to the events they face (Yamey, 2001). However, there are a number of studies that attest to the high level of stress faced by physicians and the need to implement techniques to increase well-being in medical school methodology (Hayes, Prihodova, Walsh, \& Doyle, 2017; Zaré, Galanko, Behrns, Koruda, Boyle et al., 2004).

Relationships between empathy, burnout and wellbeing among medical students

It is well known that the medical professions are characterized by a high load, a large number of working hours, high pressure, stressful environment and a close doctor-patient relationship. All this can lead to serious physical and mental health problems, such as anxiety, depression and burnout. These possible mental problems have detrimental effects on quality of life and satisfaction with life or well-being, which can have a negative impact on the quality of medical acts performed (Yuguero, Melnick, Marsal, Esquerda, Soler-Gonzalez, 2018; Yuguero, Marsal, Buti, Esquerda, Soler-González, 2017).

One of the important factors mentioned in the literature as being associated with burnout is empathy (Duarte \& Pinto-Gouveia, 2017; Silver, Caleshu, Casson-Parkin, Ormond, 2018). For this reason, serious importance is given to empathy in the years of professional training of medical students, this being an essential stage for the "construction" and training of competent doctors. The development of empathy in students is therefore considered an end in itself in medical schools (Shapiro, 2008).

The negative association between empathy and burnout among medical specialists has been documented and explained in numerous studies (Pensec \& Selic, 2018). Regarding the correlations between empathy and burnout in students, these have been demonstrated by relevant studies over time (Paro, Silveira, Perotta, Gannam, Enns, \& Giaxa, 2014). A study of a sample of 265 medical students showed that empathy measured with the Jefferson Scale for Empathy (JSE) correlated positively with personal achievement and negatively with depersonalization as facets of burnout (Hojat, Vergare, Isenberg, Cohen, \& Spandorfer, 2015). Lucchetti et al. (2018) conducted a cross-sectional study comparing the differences between medical students in America and those in Brazil in terms of quality of life, mental health, empathy and burnout. The results showed that American students scored higher on empathy than Brazilian students, while on burnout they scored lower.

Consistently, studies have shown that burnout is significantly negatively associated with life satisfaction among medical students and physicians. Life satisfaction is 
the cognitive aspect of psychological well-being and is defined as the conscious assessment that the individual makes of his life according to the standards set by himself (Diener, Emmons, Larsen, \& Griffin, 1985). A study of a sample of 452 pharmacy students enrolled at five universities in South Korea showed that exhaustion and cynicism, as facets of burnout, are significantly negatively associated with well-being (Cho \& Jeon, 2018). A sevenyear longitudinal study of 3255 Finnish dentists showed that burnout predicts depressive symptoms and decreases wellbeing (Hakanen \& Schaufeli, 2012). Demerouti et al. (2000) showed that there are significant negative correlations between burnout and disengagement as facets of burnout and life satisfaction among 109 nurses in Germany.

Given the close link between burnout and well-being, as well as the important role of empathy, we aim to test whether empathy moderates the relationship between burnout and well-being among students, formulating the following hypothesis:

H3. Empathy moderates the relationship between burnout and well-being.

\section{The present study}

The present study aims to analyze the relationships between empathy, burnout and the well-being of students, and also the differences regarding burnout, empathy and well-being according to their specialization. The need to study this topic comes from the experiences that medical students live during the six years of college and even during the residency. Medical schools are known for the high

\section{METHODOLOGY}

\section{Participants and procedure}

The study was attended by 270 students aged between 18 and 48 years, $M=20.84, S D=3.26$. Of these, 94 are males (35\%) and 176 are females (65\%), 143 report they are single (53\%), and 127 report they are in a relationship (47\%). Regarding the specialization, 83 are enrolled at the Faculty of Dentistry, University Titu Maiorescu (31\%), 73 are enrolled at the University of General Medicine and Pharmacy Carol Davila (27\%), and 114 are enrolled at the Faculty of Psychology and Educational Sciences, University of Bucharest (42\%). 96 students are in year $1(36 \%), 79$ students are in year $2(29 \%), 53$ students are in year 3 $(20 \%)$, nine students are in year $4(3 \%), 25$ are in year 5 (9\%) and eight students are in year $6(6 \%)$.

The present study is a non-experimental, transversal, correlational and differential one. The data was collected through a Google form that included three questionnaires and was distributed through social networks to students in the faculties of medicine and psychology. The first two sections of the questionnaire included informed consent and agreement to the processing of personal data. After marking volume of academic load, for the pressure put on students to prepare in time to meet deadlines and achieve high performance. After completing the six years of medical training, the students' effort continues with that of preparing for the residency exam. In essence, medical school is a long, tiring and demanding one.

Moreover, a pressing problem is that too few places are made available to students each year for residency, which leads to increased stress levels. Many students thus experience states of anxiety and even depression, as well as beliefs of helplessness, inefficiency, hopelessness, inadequacy. Burnout as an extreme form of mental pressure, accumulated during college, can be a negative predictor of well-being, and empathy may moderate this relationship. Student exhaustion can lead to a decrease in well-being, which can endanger not only students' mental health but also their abilities and their subsequent professional, and this decrease may be influenced by students' level of empathy. The interaction between burnout and empathy can be associated with a certain level of psychological well-being.

We believe that this study can be useful for reflecting the current state of medical students, but also for sounding the alarm regarding the academic load and academic obligations with high potential stressor, assuming also that medical students have higher levels of burnout and lower levels of empathy and well-being.

these sections, students were able to complete the items related to each questionnaire, as well as a set of sociodemographic data. Thus, the sampling method was one of convenience, applying the principle of the snowball sampling method, according to which each student sent the questionnaire to other colleagues who would have wanted to participate in the study.

The data were collected between October and December 2020 and the only inclusion criterion was that students be enrolled in a medical or psychology faculty.

\section{Instruments}

Burnout was measured with the Academic Burnout Scale (Zhang, Shi, Yun, Li, Wang, He, \& Miao, 2015). The instrument comprises 15 items scored on a Likert scale from 1 to 5 , where 1 - total disagreement and 5 - total agreement. The burnout level is obtained by summing all the items, the high scores reflecting a high level of burnout. Examples of items: "I feel emotionally drained from college", "I feel powerless at the end of a college day". 
Empathy was measured with the Jefferson Scale of Empathy (JSE) (Hojat, Maxwell, Carroll, \& Cass, 2016). The instrument comprises 20 items and presents different forms for doctors, patients, medical students or students at other faculties with a human profile. In the present study, two of the variants were applied, namely the form for medical students and the form for psychology students. Scores are offered on a seven-step Likert scale, where 1 - strong disagreement and 7 - strong agreement. Examples of items: "Patients feel better when their doctors understand their feelings" or "Empathy is a therapeutic skill without which the doctor's success is limited." The overall level of empathy is calculated by summing the scores obtained on the 20 items, the high scores showing high levels of empathy.
Well-being was measured with The Satisfaction with Life Scale (SWLS) (Diener, Emmons, Larsen, \& Griffin, 1985). The instrument contains five items scored on a seven-step Likert scale, where 1 - strongly against and 7 - strongly agree. Example item: "The conditions of my life are excellent." The overall score is calculated by summing the scores offered for each item, and the high scores reflect a higher level of well-being.

In order to organize the data and test the hypotheses, the statistical analysis program IBM SPSS 24 (IBM Corp, 2016) and the medmod module from Jamovi (The jamovi project, 2021) were used.

\section{RESULTS}

\section{Descriptive statistics}

Table 1. Mean scores, standard deviations, internal consistency coefficients, and correlations between variables

\begin{tabular}{|c|c|c|c|c|c|c|}
\hline & M & SD & a & Empathy & Burnout & Well-being \\
\hline Empathy & 107.12 & 16.10 & .82 & 1 & & \\
\hline Burnout & 51.21 & 17.88 & .79 & $-.44^{\star \star}$ & 1 & \\
\hline Well-being & 25.15 & 5.80 & .88 & $.17^{\star \star}$ & $-.39 * \star$ & 1 \\
\hline
\end{tabular}

${ }^{\star *} . p<.01$

\section{Hypotheses testing}

H1. Medical students have lower levels of empathy than psychology students.
In order to test this hypothesis, an independent smples t-test was performed.

Table 2. Mean scores for empathy according to specialization (medicine/psychology)

\begin{tabular}{llrlrr}
\hline & Faculty & $\mathrm{N}$ & $\mathrm{M}$ & $\mathrm{SD}$ & $\mathrm{SEM}$ \\
\hline Empathy & Medicine & 156 & 101.61 & 16.30 & 1.31 \\
& Psychology & 114 & 114.67 & 12.39 & 1.16 \\
\hline
\end{tabular}

Table 3. Independent samples t-test for empathy according to specialization (medicine/psychology)

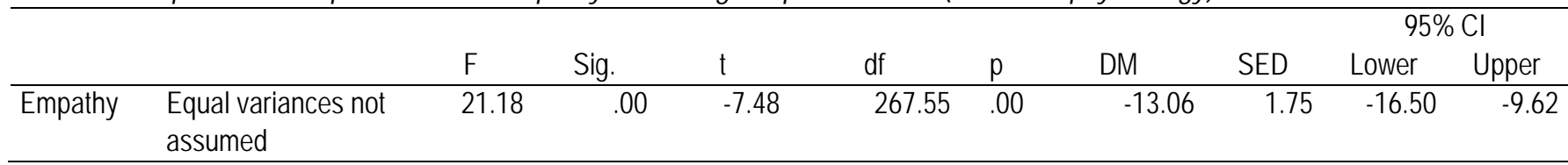

It is observed that medical students register lower levels of empathy than psychology students, $M=101.61, S D=16.30$ compared to $M=114.67, S D=12.39$, the difference being statistically significant, $\mathrm{t}(267.55)=-7.48, \mathrm{Cl} 95 \%(-16.50$, 9.62), $p<.01$, the effect size being $d=.09$.
Given this result, we can say that the $\mathrm{H} 1$ hypothesis is supported by the analyzed data.

H2. Medical students have higher levels of burnout than psychology students

In order to test this hypothesis, an independent smples t-test was performed. 
Table 4. Mean scores for burnout according to specialization (medicine/psychology)

\begin{tabular}{llrrrr}
\hline & Faculty & $\mathrm{N}$ & $\mathrm{M}$ & $\mathrm{SD}$ & $\mathrm{SEM}$ \\
\hline Burnout & Medicine & 156 & 54.62 & 18.22 & 1.46 \\
& Psychology & 114 & 46.55 & 16.36 & 1.53 \\
\hline
\end{tabular}

Table 5. Independent samples t-test for burnout according to specialization (medicine/psychology)

\begin{tabular}{|c|c|c|c|c|c|c|c|c|c|c|}
\hline & & \multirow[b]{2}{*}{$\mathrm{F}$} & \multirow[b]{2}{*}{ Sig. } & \multirow[b]{2}{*}{$t$} & \multirow[b]{2}{*}{$d f$} & \multirow[b]{2}{*}{$p$} & \multirow[b]{2}{*}{ DM } & \multirow[b]{2}{*}{ SED } & \multicolumn{2}{|c|}{$95 \% \mathrm{Cl}$} \\
\hline & & & & & & & & & Lower & Upper \\
\hline Burnout & $\begin{array}{l}\text { Equal variances } \\
\text { assumed }\end{array}$ & .92 & .34 & 3.75 & 268 & .00 & 8.07 & 2.15 & 3.83 & 12.30 \\
\hline
\end{tabular}

It is observed that medical students register higher levels of burnout than psychology students, $M=54.62, A S=18.22$ compared to $M=46.55, A S=16.36$, the difference being statistically significant, t $(268)=3.75, \mathrm{Cl} 95 \%(3.83,12.30)$, $p<.01$, the effect size being $d=.01$.
H3. Empathy moderates the relationship between burnout and well-being.

In order to test this hypothesis a moderation analysis was performed with burnout as independent variable, well-being as dependent variable, and empathy as moderator variable.

Table 6. Moderation estimates for empathy in the relationship between burnout and well-being

\begin{tabular}{|c|c|c|c|c|c|c|}
\hline & \multirow[b]{2}{*}{ Estimate } & \multirow[b]{2}{*}{ SE } & \multicolumn{2}{|c|}{ 95\% Confidence Interval } & \multirow[b]{2}{*}{ Z } & \multirow[b]{2}{*}{$\mathrm{p}$} \\
\hline & & & Lower & Upper & & \\
\hline Burnout & -.12 & .02 & -.16 & -.09 & -6.79 & .00 \\
\hline Empathy & -.01 & .02 & -.05 & .03 & -0.39 & .70 \\
\hline Burnout $*$ Empathy & .02 & .00 & .01 & .03 & 2.65 & .01 \\
\hline
\end{tabular}

Table 7. The effect of burnout on well-being at different levels of empathy

\begin{tabular}{|c|c|c|c|c|c|c|}
\hline & \multirow[b]{2}{*}{ Estimate } & \multirow[b]{2}{*}{ SE } & \multicolumn{2}{|c|}{ 95\% Confidence Interval } & \multirow[b]{2}{*}{ z } & \multirow[b]{2}{*}{$p$} \\
\hline & & & Lower & Upper & & \\
\hline Average & -.12 & .02 & -.16 & -.09 & -6.68 & .00 \\
\hline Low (-1SD) & -.18 & .03 & -.23 & -.13 & -6.76 & .00 \\
\hline High (+1SD) & -.07 & .03 & -.13 & -.01 & -2.34 & .02 \\
\hline
\end{tabular}

It is observed that empathy moderates the relationship between burnout and well-being, the moderation estimate being $b=.02, \mathrm{Cl} 195 \%(.01, .03), \mathrm{Z}=-6.79, \mathrm{p}<.01$. At low levels of empathy, the negative effect of burnout on wellbeing is more pronounced, $b=-.18, \mathrm{Cl} 95 \%(-.23,-.13), \mathrm{Z}=$

\section{DISCUSSION}

The present study highlighted the relationships between burnout, empathy and the well-being of students.
$-6.76, p<.01$, at average levels of empathy is moderate, $b=$ $-.12, \mathrm{Cl} 95 \%(-.16, .09), \mathrm{Z}=-6.68, \mathrm{p}<.01$, and at high levels of empathy decreases significantly, $b=-.07, \mathrm{Cl} 95 \%(-.13$, $.01), Z=-2.34, p<.05$.

The descriptive statistics showed that the level of students' burnout, although below average, still records high scores. Burnout itself should not be allowed to reach high levels as 
possible interventions could be applied. The level of empathy and well-being of the students were also increased. This may also be due to the fact that data were collected in the first academic semester, before the winter holidays, when students generally do not have very high levels of stress, the pressure being reduced by the large time distance from exams and projects in the evaluation sessions.

The $\mathrm{H} 1$ hypothesis showed that medical students have lower levels of empathy than psychology students. It is possible that this result also comes from the psychic construction of the participants, in the sense that psychology students tend to choose this specialization precisely starting from the fact that they have high levels of empathy. Then, the probability of practicing a "soul" profession such as psychology, strengthens this feature during vocational training. In addition, the academic disciplines within the faculties of psychology are rather oriented on the nonphysiological area of the human being, also leading to the development of empathy. The academic disciplines within medical schools focus mainly on physiology, diseases, medical interventions. Moreover, medical students need to get used to the idea that they will have to treat "cases", that they will have to focus on the medical side so that they are not affected by the patient's or his own emotionality.

Through the $\mathrm{H} 2$ hypothesis, it was shown that burnout is higher in medical students than in psychology students. This result can be attributed to the fact that between October and December 2020, due to the pandemic, psychology students had courses exclusively online, which helped them to take the necessary protection measures, but also to benefit from the protection offered by their own house. On the other hand, medical students, although they took part in online courses, did not stop from physically attending college to conduct laboratory or practice classes. Moreover, some of the medical students volunteered to help doctors fight the COVID-19 pandemic.

To these can be added the difference in curricular load, the medical school being known as having a more complex curriculum than any other faculty. There are more disciplines, more demanding laboratories, so it becomes natural for medical students to often feel overwhelmed by their academic responsibilities, above their peers at other faculties.

Through the H3 hypothesis, we aimed to test whether empathy moderates the relationship between burnout and well-being, the results showing that indeed, at high levels of empathy this relationship decreases in intensity.

This result may be caused by the specificity of the burnout and its characteristics marked by cynicism, exhaustion and disengagement in the activity. Cynicism is in itself a form of cold and mischievous humor that shows interlocutors lack of understanding and compassion, exhaustion is a maximum form of fatigue in which personal resources are difficult to access, so the person is primarily concerned with saving their own strength and not saving the emotions of others. Disengagement is the loss of interest in successfully completing professional or academic goals, which can drastically reduce attention to others, especially to those in the same context (colleagues, patients, teachers).

Results obtained by us are congruent with those of previous studies. Thus, Wang, Wang, Shi, Li, Liu et al. (2019), in a cross-sectional study on empathy, burnout and life satisfaction in which 1271 medical students from China participated, showed that the level of empathy of students decreases from one academic year to another, but the level of burnout and satisfaction with life remains constant. Empathy correlated with age and year of study, and burnout with the mother's level of education. Life satisfaction was explained in a proportion of $6 \%$ by empathy and in a proportion of $14 \%$ by burnout.

In a study on the relationship between burnout and empathy among medical students in which 353 students participated, von Harscher, Desmarais, Dollinger, Grossman, and Aldana (2017) showed that there is a significant negative correlation between burnout and empathy and that the level of burnout differs depending on the type of empathy. Thus, students with elevated levels of empathic concern had lower burnout scores, while students with high depersonalization had higher levels of burnout.

Regarding the differences between medical and psychology students in burnout, there are numerous studies that highlight the sources of stress that affect medical students. These need to be considered, but first of all, identified. These include extended hours of activity and sleep deprivation. High load involves high requirements for students, including assessment tests, clinical simulations, projects, practical and laboratory activities. These problems may become much more pronounced against a background of lack of support from teachers or an insensitive academic environment (Mitchell, Matthews, Grandy, \& Lupo, 1983). Regarding sleep deprivation, numerous studies have shown that it is associated with fatigue, burnout and increased risk of medical errors (Asken \& Raham, 1983). A cross-sectional study showed that most participating residents reported that they need to learn in order to tolerate sleep deprivation and that this phenomenon is a "natural" part of training (Lin, Liebert, Tran, Lau, \& Salles, 2016). Another source of stress is emotional exhaustion caused by contact with sick or terminally ill patients. Medical students and residents need to learn how to manage this type of interpersonal contact. Learning to deal with these situations and build adaptive coping strategies is a challenge for both students and residents. This learning is rarely "taught" in college, students having to get used to the situation and adapt to it. The decisions that must be made regarding the medical 
situation of certain patients, as well as the relationship with their family members, also contribute to this source of stress.

Lack of time for personal life is another source of stress for students. Studies show that the level of burnout depends more on the lack of free time generated by complex academic activities and not necessarily on the activities themselves (Brent \& Brent, 1978). It is unanimously accepted that understanding how to balance academic (or professional) life with personal life leads to the promotion of a healthy and fulfilled life. Thus, personal stressors contribute to and add to the cumulative stress of students and residents.

College years coincide with years of major life events, and this can be another source of stress. Marriage, the birth of a child, finding a job or looking for a job are just some of the major sources of human stress (Mushin, Matteson, \& Lynch, 1993). Family obligations are an additional source of stress, the cost of living increases on all fronts, free time is critically limited.

\section{Conclusions}

The present study aimed firstly to analyze the relationships between burnout, empathy and well-being among students and secondly to identify differences in the levels of burnout and empathy in medical students compared to those of psychology. It has been observed that medical students have higher levels of burnout and lower levels of empathy. Increased levels of empathy lead to a decrease in the intensity of the negative relationship between burnout and well-being. Possible causes of stress leading to burnout and decreased empathy among medical students were discussed.

The consequences of burnout can be dramatic, so it is imperative to detect them early. Among the most common signs are distress and depression. To these is added distrust in professional training. Most medical students say they are afraid to ask for help when they need to make a decision about academic tasks or the medical cases they work with. This phenomenon leads to lack of initiative and anxiety, distrust of one's own skills and limitation of one's vision of one's career.

Another consequence of burnout is dropping out of school. A large number of students say they are overwhelmed by academic tasks and are forced to look for other career opportunities. The later the waiver, in the fifth or sixth year of study, the stronger the feeling of inadequacy, unhappiness, non-fulfillment. There are many cases where students and residents with high levels of stress resort to self-destructive behaviors such as alcohol or drug use. Alcohol consumption and smoking have been found to be positively associated with burnout levels. Finally, the suicide rate is higher among medical students and residents than among other students. Studies have shown that suicide kills more people than diabetes, lung disease or liver disease.

Burnout can be prevented rather than treated because the costs become lower. An unfavorable academic environment can be combated by providing positive learning opportunities, engaging students in meaningful and relevant activities for their future profession, supporting them through flexible academic programs. Overlapping the requirements of personal life with those of academic life and the stress caused by it can be mitigated by re-evaluating curricula or by offering alternative training options, such as learning at home or recovering missed hours at times when students need time.

\section{Practical implications of the study}

Based on the results of this study, personal development programs for students can be developed and implemented in medical schools. These could include sessions of learning and training adaptive coping strategies, time management, organization and optimal balancing of personal life requirements with the academic one.

Curricula could be adapted to be covered both physically and online, so that students have the freedom to organize their time according to all levels of life, without focusing exclusively on academic responsibilities. Team-building sessions can be organized to intensify group cohesion, to bring students together, to facilitate interactions between them or even mentoring programs in which senior students to accompany beginners and provide guidance starting from to their own experiences. Communication with teachers could be greatly improved if the so-called "power distance" were reduced, if teachers were more open and available, if they offered their support before being asked to do so.

\section{Limits and future directions of research}

One of the limitations of this study is that the number of participants is relatively small. This can be attributed to the fact that the information regarding this research approach was made exclusively in the online environment, and many of the students ignored the announcements made in this regard. As a future direction of research, we aim to approach students from several faculties and specializations, and the testing to be done in face-to-face meetings.

Another limitation of the study is the application of selfreporting instruments, which could to some extent distort the quality of the answers provided by students. In the future we will try to use other methods of data collection, such as observation sheets or qualitative analyzes. Also, this study may be the basis for possible longitudinal studies, the results obtained by us thus constituting the baseline level in this direction. 


\section{REFERENCES}

Ahola, K., Hakanen, J. (2007). Job strain,burnout,and depressive symptoms: A prospective study among dentists. Journal of affective disorders, 104(1), 103-110. doi: 10.1016/j.jad.2007.03.004

Asken, M. J., Raham, D. C. (1983) Resident performance and sleep deprivation: a review. J Med Educ, 58, 382-388. doi: 10.1097/00001888-198305000-00003.

Baron-Cohen, S. (2001). Theory of mind in normal development and autism. Prisme, 34, 174-183.

Baron-Cohen, S., \& Wheelwright, S. (2004). The empathy quotient: An investigation of adults with Asperger syndrome or high functioning autism, and normal sex differences.

Journal of Autism and Developmental Disorders, 34, 163175. doi:10.1023/B:JADD.0000022607.19833.00

Batson, C. D. (1991). The altruism question: Toward a social psychological answer. Hillsdale, NJ: Erlbaum.

Brent, R. L, Brent, L. H. (1978) Medicine an excuse from living. Res Staff Physician, 24, 61-65.

Byrne, B. M. (1994). Burnout: testing for the validity, replication, and invariance of causal structure across elementary, intermediate, and secondary teachers. American Educational Research Journal, 645-673. https://psycnet.apa.org/doi/10.2307/1163231

Cho, E., Jeon, S. (2019). The role of empathy and psychological need satisfaction in pharmacy students' burnout and well-being. BMC Medical Education, 19:43-54. https://doi.org/10.1186/s12909-019-1477-2

Davis, M. H. (1983). Measuring individual differences in empathy: evidence for a multidimensional approach. Journal of Personality and Social Psychology, 44(1), 113-126. http://dx.doi.org/10.1037/0022-3514.44.1.113

Del Canale, S., Louis, D. Z., Maio, V., Wang, X.,Rossi, G., Hojat, M., Gonnella, J. S. (2012). The relationship between physician empathy and disease complications: An empirical study of primary care physicians and their diabetic patients in Parma. Academic Medicine, 87, 1243-1249. doi: 10.1097/ACM.0b013e3182628fbf.

Demerouti, E., Bakker, A. B., Nachreiner, F., Schaufeli, W. B. (2000). A model of burnout and life satisfaction amongst nurses. J Adv Nurs, 32(2), 454-64. http ://dx.doi.org/10.1046/j.1365-2648.2000.01496.x

Diener, E., Emmons, R. A, Larsen, R. J., Griffin, S. (1985). The satisfaction with life scale. J Pers Assess, 49, 71-5. doi: 10.1207/s15327752jpa4901_13

Diener, E., Emmons, R. A., Larsen, R. J., \& Griffin, S. (1985). The Satisfaction With Life Scale. Journal of Personality Assessment, 49(1), 71-75. https://doi.org/10.1207/s15327752jpa4901_13

Duarte, J., Pinto-Gouveia, J. (2017). Empathy and feelings of guilt experienced by nurses: a cross-sectional study of their role in burnout and compassion fatigue symptoms. Appl Nurs Res., 35, 42-7. doi: 10.1016/j.apnr.2017.02.006
Dyrbye, L., Shanafelt, T. D., Sinsky, C. A., Cipriano, P., Bhatt, J., Ommaya, A., . . . Meyers, D. (2017). Burnout Among Health Care Professionals: A Call to Explore and Address This Underrecognized Threat to Safe, High-Quality Care. NAM Perspectives. https://doi.org/10.31478/201707b. Ekman, P., Friesen, W. (2003). Unmasking the face. Cambridge, MA: Malor Books.

Ford, M. E. (1982). Social cognition and social competence in adolescence. Developmental Psychology, 18, 323-340. https://psycnet.apa.org/doi/10.1037/0012-1649.18.3.323

Hakanen, J. J., Schaufeli, W. B. (2012). Do burnout and work engagement predict depressive symptoms and life satisfaction? A three-wave seven-year prospective study. J Affect Disord., 141, 415-24. doi: 10.1016/j.jad.2012.02.043 Hayes, B., Prihodova, L., Walsh, G., \& Frank Doyle, S. D. (2017). What's up doc? A national cross-sectional study of psychological wellbeing of hospital doctors in Ireland. BMJ Open. http://dx.doi.org/10.1136/bmjopen-2017-018023

Hojat, M., Vergare, M., Isenberg, G, Cohen, M, Spandorfer, J. (2015). Underlying construct of empathy, optimism, and burnout in medical students. Int J Med Educ., 6, 12-6. doi: 10.5116/ijme.54c3.60cd.

Hojat, M. (2016). The Jefferson Scale of Empathy. In M. Hojat, Empathy in Health Professions Education and Patient Care (pp. 83-128), New York: Springer International.

Hojat, M., Maxwell, K., Carroll, S., Cass, J. (2016). Jefferson Scale of Empathy. User Guide. Philadelphia, Pennsylvania, USA: Thomas Jefferson University.

IBM Corp. Released 2016. IBM SPSS Statistics for Windows, Version 24.0. Armonk, NY: IBM Corp.

Jolly, A. (1991). Conscious chimpanzees? A review of recent literature. In C. Ristau (Ed.), Cognitive ethology: The minds of other animals (pp. 231 -252). Hillsdale, NJ: Lawrence Erlbaum.

Keyes, C. L., Shmotkin, D., \& Ryff, C. D. (2002). Optimizing Well-Being: The Empirical Encounter of Two Traditions. Journal of Personality and Social Psychology, 82(6), 10071022. http://dx.doi.org/10.1037/0022-3514.82

Kumar, S. (2016). Burnout and doctors: prevalence, prevention and intervention. Healthcare, 4(3), 37. https://doi.org/10.3390/healthcare40

Lee, Y. Y., Medford, A., \& Halim, A. (2015). Burnout in physicians. J R Coll Physicians Edinb, 45(2), 104-107. doi: 10.4997/JRCPE.2015.203

Lin, D. T., Liebert, C. A., Tran, J., Lau, J. N., Salles, A. (2016) Emotional Intelligence as a Predictor of Resident WellBeing. J Am Coll Surg, 223, 352-358. doi: 10.1016/j.jamcollsurg.2016.04.044

Lucchetti, G., Damiano, R. F., DiLalla, L. F., Lucchetti, A. L. G., Moutinho, I. L. D., Ezequiel, O. D. S., et al. (2018). Crosscultural differences in mental health, quality of life, empathy, and burnout between US and Brazilian medical students. Acad Psychiatry, 42, 62-7. doi: 10.1007/s40596-017-07772 
Maslach, C. (1982). Burnout: The cost of caring. New York: Prentice Hall.

Maslach, C., \& Jackson, S. (1986). Maslach burnout inventory. Palo Alto, CA, United States: Consulting Psychologists Press.

Maslach, C., \& Leiter, M. P. (2016). Understanding the burnout experience: recent research and its implications for psychiatry. World Psychiatry, 15, 103-111. doi: 10.1002/wps.20311

Maslach, C., Schaufeli, W. B., \& Leiter, M. (2001). Job Burnout. Annual Review of Psychology, 52(1), 397-422. doi: 10.1146/annurev.psych.52.1.397

Melchers, M. C., Li, M., Haas, B. W., Reuter, M., Bischoff, L., Montag, C. (2016). Similar Personality Patterns Are Associated with Empathy in Four Different Countries. Frontiers in Psychology, 7, 290. doi: 10.3389/fpsyg.2016.00290

Michels, P., Probst, J., Godenick, M. T., \& Palesch, Y. (2003). Anxiety and anger among family practice residents:a South Carolina family practice research consortium study. Academic Medicine, 78(1), 69-79. doi: 10.1097/00001888200301000-00013

Mikulincer, M., Shaver, P. R., Gillath, O., \& Nitzberg, R. A. (2005). Attachment, caregiving, and altruism: Boosting attachment security increases compassion and helping. Journal of Personality and Social Psychology,89(5), 817839. DOI: 10.1037/0022-3514.89.5.817. 817

Mitchell, R. E., Matthews, J. R., Grandy, T. G., Lupo, J. V. (1983) The question of stress among first-year medical students. J Med Educ, 58, 367-372. doi: 10.1097/00001888198305000-00001

Mushin, I. C., Matteson, M. T., Lynch, E. C. (1993). Developing a resident assistance program. Beyond the support group model. Arch Intern Med, 153, 729-733. DOI: 10.1001/archinte.1993.00410060039007

Paro, H. B. M. S., Silveira, P. S. P., Perotta, B., Gannam, S., Enns, S. C., Giaxa, R. R. B. (2017). Empathy among medical students: is there a relation with quality of life and burnout? PLoS One, 9(4), e94133.

Pensec, L., Selic, P. (2018). Empathy and burnout in Slovenian family medicine doctors: the first presentation of Jefferson scale of empathy results. Zdr Varst., 57(3), 15565. doi: 10.2478/sjph-2018-0020.

Ryan, R. M., Deci, E. L. (2001). On happiness and human potentials: A review of research on hedonic and eudaimonic well-being. Annual Review of Psychology , 141166. https://doi.org/10.1146/annurev.psych.52.1.141

Ryff, C. D., Singer, B. (1996). Psychological Well-Being: Meaning, Measurement, and Implications for Psychotherapy Research. Sychotherapy and Psychosomatics, 65, 14-23. doi: 10.1159/000289026

Ryff, C. D., Singer, B. (1998). The contours of positive human health. Psychological Inquiry, 9, 1-28. https://doi.org/10.1207/s15327965pli0901_1
Schaufeli, W. B., Maslach, C. (1993). Historical and Conceptual Development of Burnout. Retreived at 12.01.2021,

https://www.wilmarschaufeli.n//publications/Schaufeli/043.p df

Shapiro, J. (2008). Walking a mile in their patients' shoes: empathy and othering in medical students' education. Philos Ethics Humanit Med., 3, 10-20. doi: 10.1186/1747-5341-310

Shirom, A. (1989). Burnout in work organizations. International review of industrial and organizational psychology, 25-48.

Siegel, D. J. (2012). The developing mind: How relationships and the brain interact to shape who we are. New York: Guilford Press.

Silver, J., Caleshu, C., Casson-Parkin, S., Ormond, K. (2018). Mindfulness among genetic counselors is associated with increased empathy and work engagement and decreased burnout and compassion fatigue. $J$ Genet Couns., 27, 1175-86. doi: 10.1007/s10897-018-0236-6

Vine, I. (1992). Altruism and human nature: Resolving the evolutionary paradox. In P. M. Oliner, S. P. Oliner, L. Baron, L. A. Blum, D. L. Krebs, \& M. Z. Smolenska (Eds.), Embracing the other: Philosophical, psychological, and historical perspectives on altruism (pp. 73-103). New York: New York University Press.

Vlachou, E. M., Damigos, D., Lyrakos, G., Chanopoulos, K., Kosmidis, G., \& Karavis, M. (2016). The Relationship between Burnout Syndrome and Emotional Intelligence in Healthcare Professionals. Health Science Journal, 1-9.

Von Harscher, H., Desmarais, N., Dollinger, R., Grossman, S., \& Aldana, S. (2017). The impact of empathy on burnout in medical students: new findings. Psychology, Health \& Medicine, 23(3), 295-303. doi:10.1080/13548506.2017.1374545

Wang, Q, Wang, L, Shi, M, Li X, Liu, R, Zhu, M, Wu, H. (2019). Empathy, burnout, life satisfaction, correlations and associated sociodemographic factors among Chinese undergraduate medical students: an exploratory crosssectional study. BMC Medical Education, 19, 341 https://doi.org/10.1186/s12909-019-1788-3

Wheelwright, S., Baron-Cohen, S. (2011). Systemizing and Empathizing. In D. A. Fein (Ed.), The neuropsychology of autism (pp. 317-339). New York: Oxford University Press. Whiten, A. (Ed.). (1991). Natural theories of mind: Evolution, development and simulation of everyday mindreading. Oxford, England: Blackwell.

Williams, C. A.(1989). Empathy and burnout in male and female helping professions. Research in Nursing and Health, 12, 169-178. https://psycnet.apa.org/doi/10.1002/nur.4770120307

Yuguero, O., Marsal, J. R., Buti, M., Esquerda, M., SolerGonzález, J. (2017). Descriptive study of association between quality of care and empathy and burnout in primary 
care. BMC Med Ethics, 18, 54-61. doi: 10.1186/s12910017-0214-9

Yuguero, O., Melnick, E. R., Marsal, J. R., Esquerda, M., Soler-Gonzalez, J. (2018). Crosssectional study of the association between healthcare professionals' empathy and burnout and the number of annual primary care visits per patient under their care in Spain. BMJ Open, 8, :e020949. doi: 10.1136/bmjopen-2017-020949

Zaré, S., Galanko, J., Behrns, K. E., Koruda, M. J., Boyle, L. M., Farley, D., Farrell, T. M. (2004). Psychological Well-
Being of Surgery Residents Before the 80-Hour Work Week: A Multiinstitutional Study. Journal of the American College of Surgeons, 198(4), 633-640.

Zhang, S., Shi, R., Yun, L., Li, X., Wang, Y., He, H., \& Miao, D. (2015). Self-regulation and study-related health outcomes: A structural equation model of regulatory mode orientations, academic burnout and engagement among university students. Social Indicators Research, 123(2), 585-599. https://psycnet.apa.org/doi/10.1007/s11205-0140742-3 